DOI: 10.14526/2070-4798-2020-15-3-48-55

\title{
Functional and reserve capacities of an organism estimation among sprinters according to "D\&K-TEST" indices and taking into account bioprofile
}

\author{
Ilsiyar Sh. Mutaeva ${ }^{1 *}$, Chulpan A. Gizatullina ${ }^{2}$, Aleksandra S. Seliverstova ${ }^{1}$ \\ ${ }^{1}$ Yelabuga Institute (branch) Federal State Budgetary Educational Establishment of Higher \\ Education «Kazan (Volga region) federal University, \\ Yelabuga, Russia \\ ORCID: oooo-ooo2-9387-7033, mutaeva-i@mail.ru* \\ ORCID: oooo-0002-8563-3207, Aleksa201092@mail.ru \\ ${ }^{2}$ Naberezhnye Chelny State Pedagogical University \\ Naberezhnye Chelny, Russia \\ ORCID: oooo-0oo2-8563-3207, mutaeva-ma@yandex.ru
}

\begin{abstract}
In the training process of sprinters, as well as in other cyclic kinds of sport, important place takes the training of the main structural components of muscle activity energy supply mechanisms. These, first of all, are the indices of power, volume and effectiveness. The main characteristics of muscle activity energy supply are the following: aerobic-anaerobic and alactateanaerobic orientation of the training loads. In sprint the volume of the load is characterized as considerable and great, especially at special-preparatory and competitive stages of sports training. It is important to form an integral estimation of physical loads influence, taking into account the initial level of readiness and the coefficient of physical exercises fulfillment difficulty and the zones of the training loads intensity determination, taking into account the functional state and an integral mark. Research methods and Material: scientific-methodical literature analysis, express-diagnostics of organism functional state among sprinters using "D\&K-Test" expressdiagnostics, comparative analysis of the received results. We analyzed functional state and reserve capacities indices of the organism among sprinters, who train in sports school for children and teen-agers in the training groups and the groups of sportsmanship improvement. Results. In order to estimate the initial level of sprinters' functional state we registered the indices, which characterize the power, volume, efficiency and genotype. During a long-term observation over each athlete an individual accumulation model is created, taking into account the dynamics of the registered indices with the help of "D\&K-Test" methodology. Conclusion. The results of testing functional state and reserve capacities of sprinters' organisms in a yearly cycle of training helped to define differences between the runners depending on the type of bioenergetics. In the group of the runners with an aerobic type of bioenergetics we see an average level of the ability to fulfill physical load volume in the $3^{\text {rd }}-5^{\text {th }}$ zones of intensity. In the group of the runners with an anaerobic type of bioenergetics we see a high level of organism ability to fulfill physical loads volume in the 3 rd -5 th zones of intensity. In the group of the runners with the mixed type of bioenergetics we see above the average level of organism ability to fulfill physical load volume in the 3 rd -5 th zones of intensity.
\end{abstract}

Keywords: sprinters, functional capacities, reserves of an organism, adaptation, «D\&K-Test» methodology, training cycles.

For citation: Ilsiyar Sh. Mutaeva ${ }^{1^{*}}$, Chulpan A. Gizatullina ${ }^{2}$, Aleksandra S. Seliverstova Functional and reserve capacities of an organism estimation among sprinters according to "D\&K-TEST" indices and taking into account bioprofile. Russian Journal of Physical Education and Sport. 2020; 15(3): 37-43. DOI: 10.14526/2070-4798-2020-15-3-48-55

\section{INTRODUCTION}

Atamodern stage of training highly-qualified athletes in the kinds of sport the main condition for high level of sportsmanship achievement is a correct selection and an adequate use of different training effects. At the same time, it is always important to form athletes' ability to control own functional state and correct it when necessary $[1,2]$.

The notion "Training loads in training sprinters" is understood as the influence of the exercises on an organism, the exercises, which cause active reactions of the functional systems. The degree of sprinters' organism adaptation is conditioned by the character, direction, difficulty, correspondence of coordinating difficulty and psychic tension with the specificity of sprint competitive activity with the definite volume of physical load [4].

Firstly, the orientation of the training loads 
is conditioned and changed depending on the stage, objectives of training and has a pedagogical and physiological orientation. Pedagogical orientation of physical loads is distributed by the influence on athletes' motor abilities and skills formation. Physiological orientation has a special structure, but the main is improvement, the influence of different mechanisms of muscle activity energy supply.

Modern strategy of cyclic kinds of sport development proves competitiveness of sprinters increase at world arena, especially at the Olympic Games, World Championships, Universiades and students games of different levels.

Athletes' physical development and physical health change led to the problem of sports science potentialities use, which includes progressive research methods use for the kinds of training individualization and integration. High sports results increase in sprint demands individualized and modified programs of sports training creation and their realization, taking into account individual and typological peculiarities of athletes' organisms. Physiological substantiation of sports training nowadays is a necessary part in sports reserve reorganization and training in cyclic kinds of sport.

The leading physiologists nowadays underline the necessity of a complex estimation and control over runners' functional state, taking into account the volume and duration of the training influence, defining the leading factors and phases of tiredness. In teen-age sport we often see maximum in volume and duration physical loads use, which demands constant control and estimation.

During many years the leading specialists in the sphere of physiology, biology and medicine, such as F.A. Iordanskaya, R.E. Motylyanskaya, V.S. Farfel, realize a complex diagnostics and a functional state estimation among athletes.

S.A. Dushanin and Karlenko V.P. proved the effectiveness if "D\&K TEST" use in practice of training qualified athletes. Moreover, the scientists held different research works connected with functional state and reserve capacities of organism revelation among the athletes, who go in for different kinds of sport $[3,5,6,7,8,9,10]$.

\section{RESEARCH ORGANIZATION}

The research work was held on the basis of municipal autonomous educational establishment of additional education of children sports school for children and teen-agers "Yar Chally" in Naberezhnye Chelny during 2015-2017 with the participation of students from Naberezhnye Chelny college (branch) "Volga region State Academy of Physical Culture, Sport and Tourism". We examined 22 students, who go in for sprint (17-23 years-old). All sprinters had the following categories: mass category and candidate master of sports $(n=2)$. The average experience of trainings was 6-7 years.

\section{RESEARCH METHODS}

The range of methods, which helped to estimate and analyze functional state of the sprinters, was used in the work. For the level of sprinters' functional state estimation we used express-diagnostics method with hardware and software complex "D\&K-Test" by professor S.A. Dushanin. This method was tested in the research works of many specialists. It helps to estimate the functional state and get the results, which characterize aerobic and energetic metabolism of athletes' organisms, where the important component was a sprinter's bioenergetic profile determination. The method functions owing to the principle of chest leads registration by Wilson- V3R, V1, V2, V4, V5, V6, the first derivative in chest leads by Wilson $-\mathrm{dV}_{3} \mathrm{R}, \mathrm{dV} 2, \mathrm{dV} 6$.

For the initial level of the functional state of energetic processes estimation and analysis among the runners we registered the indices, which are presented in table 1.

Table1. Functional state and reserve capacities indices of an organism among sprinters

\begin{tabular}{|c|c|c|c|}
\hline № & $\begin{array}{c}\text { Full name of the index } \\
\text { according to “D\&K-Test” }\end{array}$ & $\begin{array}{c}\text { Abridged } \\
\text { version }\end{array}$ & Characteristics \\
\hline 1 & $\begin{array}{c}\text { Anaerobic metabolic } \\
\text { capacity }\end{array}$ & ANAMC & $\begin{array}{c}\text { The ability to fulfill intensive physical and } \\
\text { other types of loads at organism maximum } \\
\text { output. The loads are mainly of anaerobic } \\
\text { orientation }\end{array}$ \\
\hline 3 & $\begin{array}{c}\text { Aerobic metabolic } \\
\text { capacity }\end{array}$ & AMC & $\begin{array}{c}\text { The ability to fulfill physical and other types } \\
\text { of loads for a long time. The loads are mainly } \\
\text { of aerobic orientation, aerobic genotype }\end{array}$ \\
\hline
\end{tabular}




\begin{tabular}{|c|c|c|c|}
\hline 5 & General metabolic capacity & GMC & $\begin{array}{l}\text { Characterizes genetically conditioned level of } \\
\text { organism capacities (capacity to act, working } \\
\text { capacity) and the ability to fulfill general } \\
\text { amount of physical and other types of loads }\end{array}$ \\
\hline 6 & $\begin{array}{l}\text { Power of creatine phosphate } \\
\text { source of energy supply }\end{array}$ & PCP & $\begin{array}{l}\text { Determines the level of iracundity, reactivity, } \\
\text { power oriented endurance, explosive force }\end{array}$ \\
\hline 7 & $\begin{array}{l}\text { Power of glycolytic source of } \\
\text { energy supply }\end{array}$ & PGL & $\begin{array}{l}\text { Determines reproductive and disposal } \\
\text { function of liver, the level of speed endurance }\end{array}$ \\
\hline 8 & $\begin{array}{l}\text { Power of aerobic source of } \\
\text { energy supply }\end{array}$ & $\begin{array}{l}\text { MOC } \\
\text { PAS }\end{array}$ & $\begin{array}{c}\text { Defines the quality of the fulfilled physical } \\
\text { load till the level of anaerobic metabolism } \\
\text { threshold }\end{array}$ \\
\hline 9 & $\begin{array}{l}\text { Threshold of anaerobic } \\
\text { metabolism }\end{array}$ & $\mathrm{W}$ tanm & efficiency, technicality, learning capability \\
\hline 10 & $\begin{array}{l}\text { Effectiveness criterion of } \\
\text { aerobic source use }\end{array}$ & $\begin{array}{l}\text { HR (heart rate) } \\
\text { tanm }\end{array}$ & $\begin{array}{l}\text { Defines pulse limits of intensity zones of } \\
\text { physical loads of different power }\end{array}$ \\
\hline 11 & $\begin{array}{l}\text { Contribution index of muscle } \\
\text { activity anaerobic supply to } \\
\text { general metabolic capacity }\end{array}$ & AHAMC/GMC- & $\begin{array}{l}\text { Anaerobic genotype of an athlete, determines } \\
\text { the speed of utilization processes in extreme } \\
\text { conditions of muscle activity }\end{array}$ \\
\hline 12 & $\begin{array}{l}\text { Contribution index of aerobic } \\
\text { supply to general metabolic } \\
\text { capacity }\end{array}$ & $\mathrm{AMC} / \mathrm{GMC}-$ & $\begin{array}{l}\text { Aerobic genotype of an athlete, determines } \\
\text { the speed of utilization processes during } \\
\text { muscle activity of moderate power }\end{array}$ \\
\hline
\end{tabular}

During a long-term observation over each athlete an individual accumulation model is created, taking into account the dynamics of the registered indices with the help of "D\&K-Test" methodology.

\section{RESEARCH RESULTS}

In the functional training of sprinters the degree of the training influence, its regulation and control are very important. The ability to choose correctly, adequately use, estimate and control is the main condition for an effective sports training organization for sprinters.

Pedagogical orientation of the training loads is characterized by physical qualities improvement and their high level support depending on the objectives of the stages of training among sprinters. Then we organize coordinately difficult movements development and sportsmanship improvement among sprinters depending on psychological readiness. Physiological orientation of the training process becomes important. It means the capacity, power and efficiency of muscle activity energy supply mechanisms increase.

The ways of energy supply are conditioned by the orientation of the training influences on sprinters' functional state: alactate-anaerobic, lactate-anaerobic, anaerobic-aerobic, aerobic training and rehabilitation. The orientation of the training influences on sprinters' organism is characterized by the indices of heart rate, maximum oxygen consumption, lungs ventilation and lactate indices. In sports practice lactate determination becomes a difficult procedure, connected with the necessity to fulfill blood sampling for analysis. Express-diagnostics methodology use without preliminarywaste of timehelps to estimatefunctional state of athletes very quickly and comfortably. Such kind of an approach helps to solve several problems: - training influences correction, taking into account the initial, current, operative and integral level of the functional state;

- physical exercises selection and specialized training complexes of general and local influence creation for the sprinters' groups of muscles; 
- percentage determination of the training influences ratio, close to competitive conditions;

- additional conditions creation for orientation change and realization according to coordinating difficulty of motor actions (low, average and high) and different level of training loads;

- special exercises inclusion into the training process, which are fulfilled in easier conditions, in the restricted space and time, which model competitive activity and conditions.

Specialists mention that functional abilities of athletes' organism are individual and are connected with genotypic conditionality of aerobic and anaerobic abilities. Energetic potential of muscle activity among sprinters is conditioned, first of all, by their organism propensity for speed and speed oriented qualities development, especially quickness of movements.

For an individual planning of sprinters' training loads we defined bioenergetic profile and the initial level of organism functional state.

Picture 1 shows the distribution of sprinters according to bioenergetic groups.

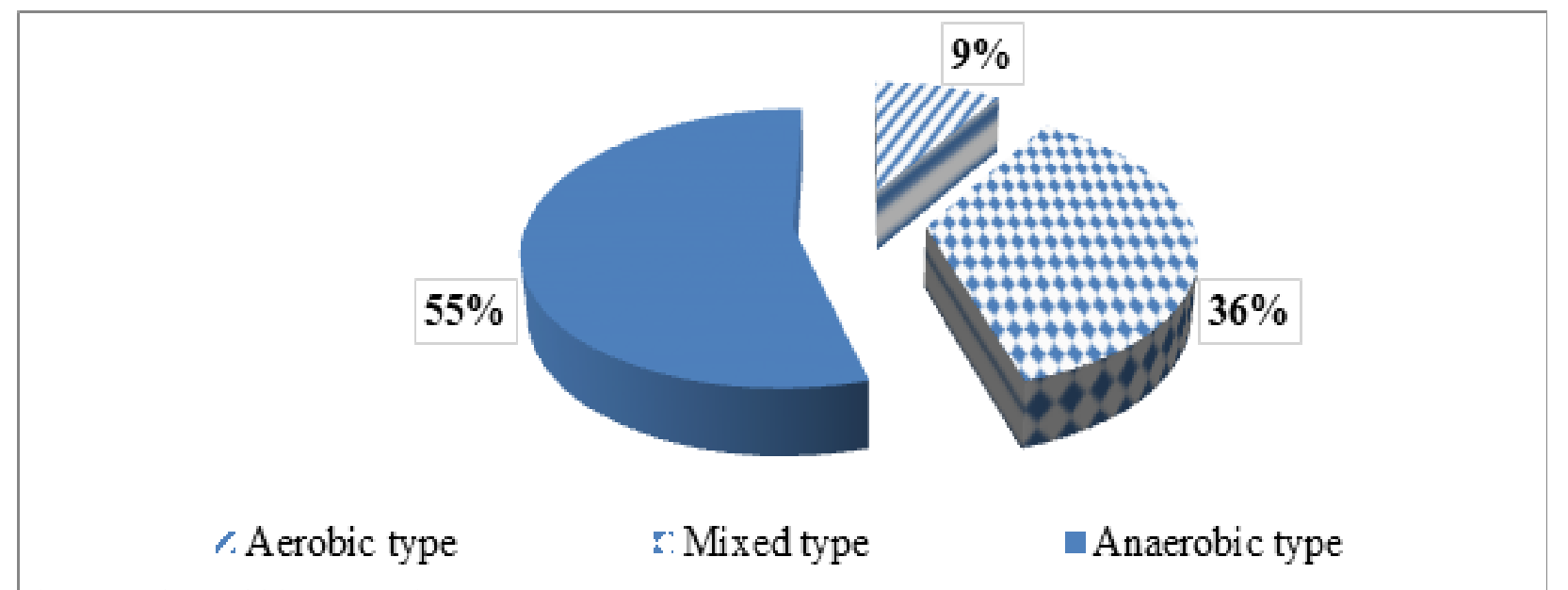

Fig. 1. Sprinters' bioenergetic type

Picture 1 shows that $9,1 \%(n=2)$ of the runners belong to aerobic type. $36,4 \%(n=8)$ belong to the mixed type. $54,5 \%(\mathrm{n}=12)$ of the runners belong to anaerobic type and they formed the biggest part of the respondents. It was revealed that among sprinters the $3^{\text {rd }}, 4^{\text {th }}$ and the $5^{\text {th }}$ bioenergetic groups prevail, which are characterized by the prevalence of mixed and anaerobic types of muscle activity energy supply, high level of technicality and reactivity. In the $5^{\text {th }}$ group of sprinters the abilities to fulfill intensive physical and other types of load at organism maximum output prevail. They have mainly alactate-anaerobic and anaerobic orientation.

Picture 2 presents the indices of functional and reserve capacities of sprinters' organism, taking into account their bioenergetic type.

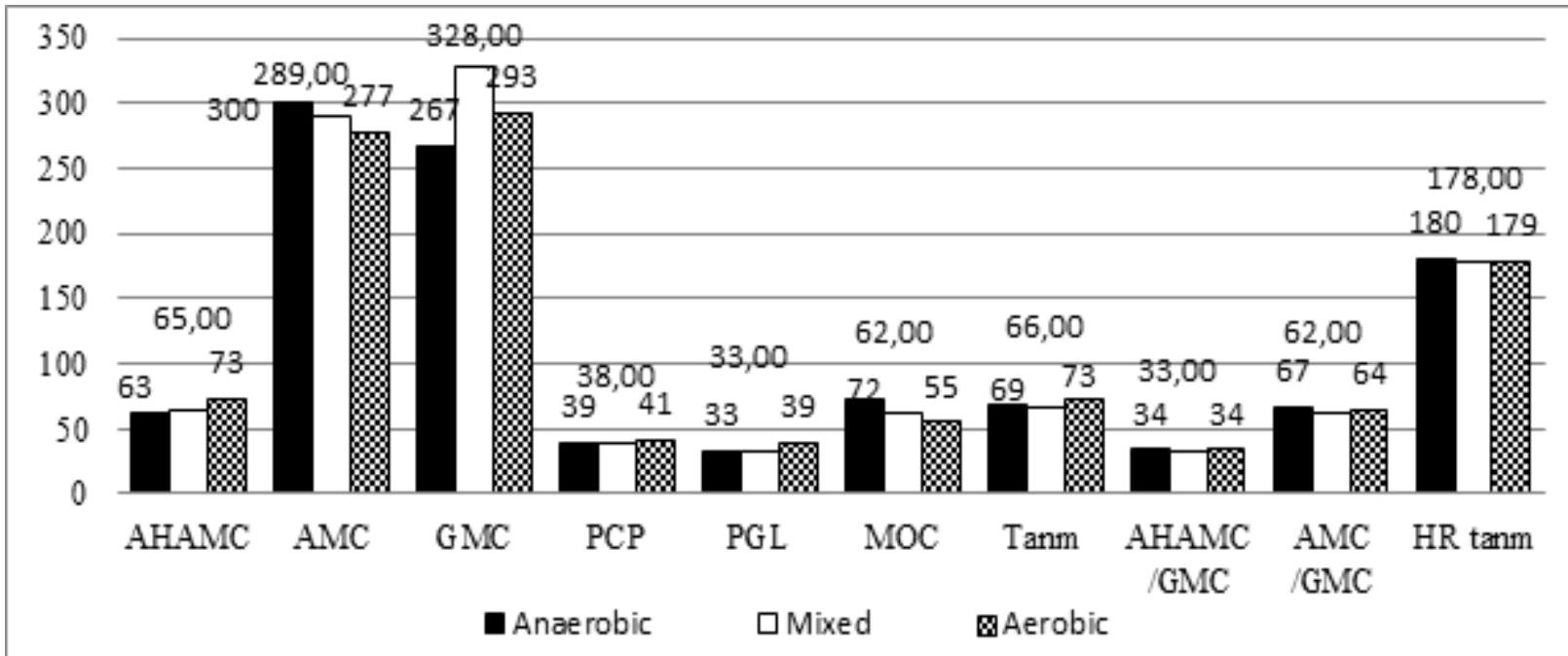

Fig. 2. Indices of functional and reserve capacities of sprinters' organism, taking into account bioenergetic profile, (c.u.) 
Taking into account the received results we held a comparative analysis of the studied indices of the functional and reserve capacities of sprinters' organism.

The first index is anaerobic metabolic capacity. Among sprinters in the examined groups it didn't differ much, but the absolute values among the runners with anaerobic type of bioenergetics are higher $(73,00 \pm 0,96$ c.u.). It is connected, first of all, with the fact that these runners have a distinct structural component of muscle activity energy supply, which is capacity. Absolute values in the groups of aerobic and mixed type didn't differ much and are revealed in terms of an individual model of anaerobic metabolic capacity demonstration. Individual indices of anaerobic metabolic capacity among the runners of all studied types of bioenergetics were within the fluctuations range from 2 -265 c.u.

In the indices, which characterize aerobic metabolic capacity of sprinters we see the values within the range from 240 to 320 c.u., which characterize the ability of an organism to fulfill physical load volume in the $1^{\text {st }}-2^{\text {nd }}$ and partially in the $3^{\text {rd }}$ zones of intensity. Sprinters with aerobic type have higher values, as the evidence that they have aerobic genotype. Fluctuations range between the groups was 23 c.u. (picture 2).

In the indices of general metabolic capacity, which characterize the level of sprinters' working capacity, we see high values of: aerobic type-267,01 $\pm 3,23$ c.u.; mixed type $-328,54 \pm 3,23$ c.u.; anaerobic type $-293,01 \pm 1,23$ c.u.. It means that the ability of sprinters to fulfill the planned volume of physical loads has the average level of demonstration within the range of normative values.

The next index of considered by us power of creatine phosphate source of energy supply among sprinters determined the level of power endurance, explosive force and is within the range of normal values according to the program of the registered indices with the help of "D\&K-Test" methodology. The runners of the anaerobic, mixed type and aerobic type have the indices, which characterize the power of creatine phosphate source of energy supply and are at the same level and within the range of normal fluctuations. Therefore the training loads among the runners had more power oriented direction.

Power of glycolytic source of energy supply among sprinters with anaerobic type is more distinct 39,01 $\pm 0,96$ c.u. and it characterizes more distinct speed abilities demonstration and a high level of readiness for maximal power work among the representatives of anaerobic type.

Maximal oxygen consumption is the index of physical load value till the level of anaerobic metabolism threshold. In the group of the runners with anaerobic type we see the values considerably lower, than among the runners with aerobic and mixed type. Therefore the training loads of speed and speed-oriented character don't fully reveal the power of aerobic source. The power of aerobic source of energy supply development is necessary using the training loads fulfilled in the $1^{\text {st }}-3^{\text {rd }}$ zones of intensity.

In the indices, which characterize the threshold of anaerobic metabolism and which play the role of effectiveness and efficiency criterion of aerobic source use, all sprinters have high level of their demonstration (picture 2).

The index, which characterizes the contribution of anaerobic supply to general metabolic capacity, reflecting anaerobic genotype of an athlete, determines speed of utilization processes in extreme conditions of muscle activity. In our example it is has above the average level.

The index, which characterizes the contribution of aerobic supply to general metabolic capacity among sprinters of aerobic group turned out to be higher $39,01 \pm 0,96$ c.u.

Sprinters, who belong to the mixed type, are genetically inclined to optimally balanced level of muscle activity energy supply. However, this statement helps to organize reassessment of own individual abilities in terms of maximal stress. During the training lessons runners can feel confidence and during the competitions they can be not very successful.

The examined indices analysis revealed the necessity to reconsider the training influences on the runners' organism, especially of aerobic orientation. As aerobic load helps a sprinter train according to the mixed scheme of an optimal ratio of training and competitive loads volume and intensity, according to the principle of a wavy distribution. This principle realization provides the possibilities increase of great volumes of physical loads fulfillment with intensity increase. Clear contribution of anaerobic supply to general metabolic capacity helps to use alternation of big and maximal loads, especially in accelerated training micro cycles. However, in this case there is the necessity, especially for anaerobic type runners, to include aerobic loads regularly not only as the training, but mainly as a rehabilitation aim. In precompetitive training of sprinters we need to estimate not only the current, but also an operating functional state of an organism. If the studied indices of runners are in the necessary zone of indices fluctuations, the range of their changes is defined both in the highest and the lowest degree. If the functional state indices of energy supply system don't achieve necessary level depending on the level of sprinters' readiness, it is recommended to increase the volume and intensity of the recommended training load. If the indices, which characterize different regimens of energy supply inclusion, achieve the limits of their range, it is necessary to correct the training influences for 
tiredness and over-training state prevention.

For each bioenergetic type of runners there are recommended zones of intensity, which change depending on the functional state of a runner during sports training.

The recommended zones of intensity for the runners, who belong to the mixed type, were the following: 1) regenerative - in terms of HR 135 145 beats/min; 2) aerobic - in terms of HR 150 167 beats/min; 3) aerobic-anaerobic - in terms of HR 170 - 175 beats/min; 4) anaerobic-aerobic - in terms of HR 178 - 190 beats/min; 5) anaerobic - in terms of HR more than 190 beats/min.

The recommended intensity zones of work (HR beats/min.) for the sprinters with anaerobic type were the following: 1 (regenerative) - $161-173$ beats/min.; 2 (aerobic) $174-185$ beats/min.; 3 (aerobic-anaerobic) $186-197$ beats/min.; - 198 - 209 beats/min.; 4 (anaerobic-aerobic) 5 (anaerobic) more than 209 beats/min..

\section{CONCLUSION}

The results of the sprinters' functional state and reserve capacities testing in a yearly cycle of training helped to define the differences between the runners depending on the type of bioenergetics.

Comparative analysis of the functional state indices among sprinters helped to define, that they differ depending on bioenergetic type demonstration.

In the group of the runners with aerobic type we see the average level of the ability to fulfill the volume of physical load in the $3^{\text {rd }}-5^{\text {th }}$ zones of intensity.

In the group of the runners with an anaerobic type of bioenergetics we see a high level of organism ability to fulfill physical loads volume in the 3 rd -5 th zones of intensity.

In the group of the runners with the mixed type of bioenergetics we see above the average level of organism ability to fulfill physical load volume in the 3 rd -5 th zones of intensity.

In the group of the runners with aerobic type we see a high level of the organism ability to fulfill physical loads volume in the $1^{\text {st }}$-3rd zones of intensity.

In the group of the runners with an anaerobic type we see the average level of organism ability to fulfill physical loads volume in the 1st-3rd zones of intensity.

In the group of the runners with the mixed type we see above the average level of organism ability to fulfill physical load volume in the 1st-3rd zones of intensity.

\section{REFERENCES}

1. Dushanin S.A. Express-diagnostics of athletes in non-stationary conditions. Managing the training process of highly-qualified athletes. Kiev : Health. 1985: 116-125. [In Russ.]

2. Gibadullin I.G., A.Yu. Mironov S.N. Zvereva Training process individualization among biathletes on the basis of bioenergetic types. Russian Journal of Physical Education and Sport. 2010; 5(1): 19-27. URL: http://journalsport.ru/images/vipuski/5-1/1. pdf. [In Russ., In Engl.]

3. Gibadullin I.G., Moshkina N.A., Smirnova N.M. Correlation connection of special physical readiness indices, bioenergetic and psychophysiological indices of swimmers psychophysiological parameters of swimmers. Urgent problems of physical culture and sport: Materials of the VI International scoientific-practical conference. Cheboksary. 2016: 538-541. [In Russ.] 4. Gizatullina Ch.A., Mutaeva I.Sh. The ways of training individualization among sprinters on the basis of taking into account typological peculiarities of blood circulation. Russian Journal of Physical Education and Sport. 2012; 3(24): 11-119. URL: http://journalsport.ru/images/vipuski/7-1/3.pdf. [In Russ., In Engl.]

5. Karlenko V.P., Karlenko N.V. Computer technology "D\&K TEST" use in the practice of training qualified athletes. All-Russian scientificresearch Institute of Physical Culture and Sport. Moscow. 2003: 134-136. [In Russ.]

6. Kozhevnikov V.S. Differentiated planning of the main training means among 15-16 year-old football players in the preparatory period on the basis of taking into account their bioenergetic types: abstract of dissertation of candidate of pedagogics. Naberezhnye Chelny. 2010: 23. [In Russ.]

7. Nikityuk M. V. The peculiarities of muscle activity energy supply among highly-qualified Greco-Roman wrestlers. Strategy of a healthy life style formation by means of physical culture and sport: experience and prospects of development: materials of the XII All-Russian scientific-practical conference. Part 2. Tyumen : "Vektor Buk". 2014: 147- 150. [In Russ.] 8. Pushkarev A.V. Planning training lessons of students basketball team of a higher educational establishment on the basis of functional state taking into consideration according to their types of temperament. Russian Journal of Physical Education and Sport. 2019; 14(3): 95-101. [In Russ., In Engl.]

9. Khalikov G.Z., Mutaeva I.Sh., Konovalov I.E. Training process management and control among average and long distance runners on the basis of functional state and psycho-emotional state indices study. Physical culture and Health. 2013; 1(43): 63-65. [In Russ.]

10. Vasin E., Gelfenbain A. Method and apparatus for metabolic factors determination by means of electrocardiogram. World Intellectual Property Organization. 20 February 2003. [In Russ.] 
Submitted: 12.o8.2020

\section{Author's information:}

Ilsiyar Sh. Mutaeva - Candidate of Bbiological Sciences, Professor, Elabuga Institute (branch) of Kazan (Volga) Federal University, 4236oo, Russia, Elabuga, Kazanskaya str., House 89, e-mail: mutaeva-i@ mail.ru

Chulpan A. Gizatullina - Candidate of Pedagogical Sciences, Associate Professor, Naberezhnye Chelny State Pedagogical University, 423806, RT, Naberezhnye Chelny, st. them. Nizametdinova R.M., 28, e-mail: mutaeva-i@mail.ru

Alexandra S.Seliverstova - Senior Lecturer, Yelabuga Institute (branch) of the Kazan (Volga Region) Federal University, 42360o, Russia, Yelabuga, st. Kazanskaya, house 89, e-mail: Aleksa201092@mail. ru. 